NACIONAL

\title{
El juez activista y el juez del Estado constitucional de derecho a la luz del actual proceso constituyente en Chile
}

\author{
The activist judge and the judge of the constitutional Rule of Law in light \\ of the current constituent process in Chile
}

\section{Bernardo José Toro Vera (iD}

Universidad Nacional Autónoma de México

\begin{abstract}
RESUMEN Uno de los temas necesarios en nuestro país, dado el actual proceso constituyente, es el de hacer una revisión del rol del juez en el marco del Estado constitucional de derecho y, eventualmente, una vuelta al estado de bienestar. Afirmado desde el constitucionalismo liberal en una labor restringida en el modelo de «separación de poderes» instalado desde el contractualismo de Montesquieu, la consolidación de jueces que tengan mayor campo de atribución, dada la relación simbiótica que, progresivamente, han venido teniendo el derecho constitucional y el derecho internacional de los derechos humanos, así como el rol del juzgador en tanto artífice y posibilitante de la exigibilidad y justiciabilidad de los derechos sociales, la aparición del activismo judicial, a la luz del proceso constituyente en curso en nuestro país, nos lleva a reflexionar sobre dicha figura, su naturaleza jurídica y social, y los posibles alcances en el posible nuevo Estado constitucional (y social) de derecho que se erige como demanda claramente anhelada por la ciudadanía.
\end{abstract}

PALABRAS CLAVE Activismo judicial, derechos humanos, Estado de derecho, control de convencionalidad, etapa constituyente.

ABSTRACT One of the necessary issues is our country, given the current constituent process, is to review the role of the judge in the framework of the constitutional Rule of Law and, eventually, a return to the welfare state. Affirmed from liberal constitutionalism in a restricted work in the model of "separation of Powers" installed since Montesquieu's contractualism, the consolidation of judges who have a greater scope of attribution, given the symbiotic relationship that, progressively, constitutional law has and international human rights law, as well as the role of the judge as creator and enabler of the enforceability and justiciability of social rights, the appearance of judicial activ- 
ism, in light of the ongoing constitutional process in our country, leads us to reflect on this figure, its legal and social nature, and the possible scope in the possible new constitutional (and social) State of Law that stands as a demand clearly desired by the citizens.

KEYWORDS Judicial activism, human rights, Rule of Law, conventionality control, constituent stage.

\section{Introducción}

En los siguientes párrafos, pretendo hacer una defensa del activismo judicial, en cuanto proceso que, reconociendo el desarrollo progresivo y evolutivo de consolidación hacia un Estado constitucional y democrático de derecho, rompa con el formalismo dogmático que caracterizó al Estado liberal de derecho, en el marco del avance del constitucionalismo contemporáneo, el actual proceso constituyente que vive el país, y la necesidad de consolidar un Estado social de derecho a partir de la exigibilidad y justiciabilidad de los derechos económicos, sociales, culturales y ambientales (DESCA). Para ello, primero señalo sus definiciones y las críticas que se le han hecho, para entrar en los parámetros que, a mi juicio, justifican y permiten el activismo, así como sus potencialidades presentes, sobre todo en este proceso de cambios del país.

\section{Definición y críticas en torno al activismo judicial}

No hay unanimidad al definir qué es ser un juez activista, ni de la valoración de su rol. Para Manuel Atienza (2019: 3-4), «es el que decide una cuestión jurídica de acuerdo con sus opiniones de lo que es justo, aunque ello suponga transgredir los límites fijados por el derecho». Aharon Barak (2006: 271; citado en Feoli Villalobos, 2015) lo entiende como «la tendencia judicial de lograr el equilibrio de un conflicto social a través de un cambio en la legislación vigente, mediante la creación de una nueva disposición normativa que no existía previamente, gracias a la interpretación que hace el juez de la constitución o de la ley». A su vez, el Diccionario del español jurídico lo define como la «posición fuertemente creativa de los jueces y tribunales, llevada a cabo mediante interpretaciones de la legalidad existente o a través de la cobertura de sus lagunas». ${ }^{1}$

Existe concordancia en el origen del activismo judicial a través de la estadounidense judicial review (Horn, 2010: 184-187; Breyer, 2017: 135 y ss.) (derivando en el judicial activism) (Fix Fierro 2021: 54), que lo asemeja con el rol de los órganos jurisdiccionales de ese país, lo que permitió hacer el alcance práctico de los parámetros

1. RAE, Diccionario del español jurídico, «activismo judicial», disponible en https://dpej.rae.es/lema/ activismo-judicial. 
constitucionales — especialmente en materia de derechos - a través de la práctica judicial.

Sin embargo, esta concordancia conceptual se vuelve divergente al momento de analizar la oportunidad o inconveniencia de dicho activismo. Para sus detractores, como Atienza, existiría, además de la ambigüedad terminológica señalada, una serie de falencias en la práctica del activismo judicial, cierta indeterminación en la decisión judicial -aunque Atienza le dé un tinte más conservador a la función judicial—; el traspaso del juzgador al límite prestablecido de seguir criterios ya señalados en el sistema normativo, los que establecerían - per se- «una respuesta correcta para cada caso», y que la salida a aquella regla implicaría subjetivar la decisión del juez a sus opiniones políticas; ${ }^{2}$ de que lo anterior derivaría una ambigüedad para establecer cuándo el juzgador traspasa el límite de lo prestablecido por el derecho, cayendo, eventualmente, en la indeterminación, pudiendo darse sentencias abiertamente subjetivas bajo el alero del activismo judicial (Atienza, 2019: 5-6); que dicha indeterminación también esté dada en la heterogeneidad axiológica y de entorno de los juzgadores, lo que impide ver al activismo judicial como un ente abstracto y homogéneo (Atienza, 2019: 7-8); que, por ende, el activismo judicial respondería, junto al formalismo, a aquellas conductas que el juzgador debiese tratar de evitar en absoluto en el ejercicio de sus funciones (Atienza, 2019: 9-10), dado que, recordando a Montesquieu, el juzgador solo debe ser «la boca del legislador». 3 También se encuentran las críticas relacionadas con que el juzgador que aplica el activismo judicial no se circunscribiría «a la interpretación limitada y razonable de ley o la Constitución, sino que pretenden "crear derecho nuevo"» (Fix Fierro, 2021: 54); y que, en fin, el que dicho rol implicaría, por parte del juzgador, romper la clásica división de poderes (funciones) del Estado, al darle funciones indebidas al órgano jurisdiccional (Mejía Turizo y Pérez Caballero, 2015: 30-41).

\section{Elementos que justifican al activismo judicial}

Pese a lo anterior, estimo que existen fuertes elementos que permiten justificar al activismo judicial, ${ }^{4}$ comprendiendo las aprehensiones respecto de la tradicionalmente conservadora en la composición y ejercicio de la función judicial, así como la eventual impredecibilidad de quién ocupe el activismo judicial, sin que esté siempre asegurada una interpretación progresista y protectora de los derechos humanos.

\footnotetext{
2. Véase Atienza (2019: 4) y la voz activismo judicial en Fix Fierro (2021: 54).

3. «Podría ocurrir que la ley, que es al mismo tiempo previsora y ciega, fuese, en casos dados, excesivamente rigurosa. Pero los jueces de la nación, como es sabido, no son más ni menos que la boca que pronuncia las palabras de la ley, seres inanimados que no pueden mitigar la fuerza y el rigor de la misma» (Montesquieu, 2010: 108).
}

4. Sobre este aspecto me he detenido con mayor detalle en Toro Vera (2018). 
No coincido con Atienza (2019: 12) cuando describe que el carácter conservador que caracteriza a la judicatura - respecto de otras funciones del Estado- lleve a que la aplicación del activismo judicial tenga tintes exclusivamente negativos. Baste ver el papel que ha tenido el Tribunal Supremo de Justicia estadounidense durante las presidencias de Charles Evan Hughes (1930-1941), de corte conservador, enfrentada con las políticas del New Deal de Franklin D. Roosevelt; y de Earl Warren (1953-1969), de corte progresista, como impulsora de los derechos civiles, políticos y sociales durante la década del sesenta (Epp, 2013: 24).

Se trata de superar el rol más débil del juzgador, en el ejercicio de los derechos, que tradicionalmente tuvo frente a los demás poderes o funciones del Estado. Sabido es el ánimo de la etapa del Estado liberal de derecho en su fase de libertad negativa, propio del contexto decimonónico. Nos recuerdan Mauro Cappelletti y Brian Grant que, «para la ideología liberal de los Estados burgueses de los siglos XVIII y XIX, el proceso civil estaba basado en la filosofía individualista entonces prevalecientes» (Cappelletti y Grant, 1987: 19); los derechos humanos, incluido el acceso a la justicia, tenían un carácter metafísico.

Para este tipo de juzgador, al ser los derechos liberales (incluido el de propiedad) enmarcados en la medida de «lo exigible», la hermenéutica jurídica clásica no implicaba superar la subsunción de las normas al caso concreto, sobre todo cuando los actores que más acudían ante los órganos jurisdiccionales eran, preferentemente, los que tenían el patrimonio suficiente para aquello. Ante un Estado con capacidad mínima para resolver, el rol del juzgador no superaría lo que Luigi Ferrajoli (2003: 16) identificó como Estado legalista de derecho (o paleopositivismo), de estricta aplicación del principio de legalidad a partir del derecho válido, ajeno de toda valoración axiológica, bastando su imposición por la autoridad dotada con competencia normativa respectiva. En nuestro país, esto fue gráfico a partir de la asimilación a las reglas de la hermenéutica legal dominante desde la entrada en vigor del Código Civil en 1857, siguiendo la estructuración de su símil francés, incluyendo las reglas expresas de hermenéutica jurídica, a partir de la «interpretación gramatical» (Baraona, 2010: 427-448), derivada de la escuela de la exégesis francesa (Novoa Monreal, 1981: 236). Josep Aguiló Regla caracteriza los siguientes «lugares comunes» en este tipo de Estado (legalista) de derecho: miedo a la pérdida de la neutralidad valorativa (limitándose a conocer y no razonar la norma jurídica aplicable al caso respectivo), miedo al subjetivismo (no existe juicio ético, so temor de perder la respectiva objetividad), miedo a la imposición de la moral como consecuencia de abrazar al relativismo (el juez como sujeto desprovisto de una interpretación basada en principios subyacentes a la norma jurídica) y miedo a los «claroscuros», en cuanto se use a la subsunción como regla de interpretación jurídica, de carácter binaria, fuera de toda valoración ética (Aguiló Regla, 2013: 71-76).

En la época actual, la comprensión de la labor del órgano jurisdiccional ha cam- 
biado, a partir de la concurrencia de tres factores: la consolidación del Estado social y democrático de derecho; una mayor de la simbiosis entre el derecho constitucional y el derecho internacional de los derechos humanos y el surgimiento del control de convencionalidad en el sistema regional americano; así como una mayor participación de los abogados en la formulación de litigios estratégicos.

\section{La consolidación del Estado social y democrático de derecho}

Una característica esencial del Estado legalista (o paleopositivista) de derecho es la revaloración de los principios subyacentes a las normas constitucionales, desde una premisa epistemológica esencial del derecho constitucional actual (Ferrajoli, 2016: 25-28), ${ }^{5}$ basada en las nuevas corrientes del constitucionalismo contemporáneo: el neoconstitucionalismo, el constitucionalismo popular (o democrático) y el nuevo constitucionalismo latinoamericano (Alterio, 2014: 254-255), dando paso al llamado Estado constitucional de derecho, bajo el axioma de constituciones rígidas, jerárquicamente supraordenadas a las leyes como normas de reconocimiento de su validez, y que integran la relación de reglas y principios como parámetros de interpretación. Volviendo a Ferrajoli, este Estado constitucional de derecho tiene cuatro manifestaciones: un nuevo parámetro de validez de las normas jurídicas (aunando a la parte orgánica de la Constitución con sus partes dogmática y social); una visión epistemológica de la ciencia jurídica (en su fas explicativa, crítica y proyectiva de sus propios objetivos); la convalidación, vía jurisdiccional, de las diversas normas jurídicas desde su reconocimiento de validez (en consecuencia, de su constitucionalidad basada en la identificación de las antinomias y lagunas, superando estas mediante la aplicación de las garantías constitucionales existentes); y la subordinación legal a los principios constitucionales desde su dimensión sustancial y no solo de validación formal (Ferrajoli, 2003: 19; Aguiló Regla, 2013: 80-81), lo que le da al derecho un contenido dinámico y social.

\section{Una consolidación mayor de la simbiosis entre el derecho constitucional y el derecho internacional de los derechos humanos, y la aplicación del control de convencionalidad}

Característica esencial desde mediados del siglo pasado es la irrupción del derecho internacional de los derechos humanos, a partir del proceso progresivo de instru-

5. En este sentido, el derecho constitucional en su acepción más amplia, como lo indicase en su momento el jurista mexicano Jorge Carpizo (2002: 145), «se identifica con el propio orden jurídico: es decir, la totalidad de ese derecho, ya que la base y los principios generales y fundamentales de las otras disciplinas jurídicas se encuentran en él. El derecho constitucional indica los procedimientos de creación, modificación y abrogación de todas las normas de ese orden jurídico». 
mentos internacionales ad hoc, al alero del nacimiento del sistema de las Naciones Unidas (1945), la aprobación de la Declaración Universal de los Derechos Humanos (1948), y el rico desarrollo de los diversos instrumentos internacionales en la materia, tanto a nivel internacional como regional. Esto implicó que el consiguiente corpus internacional terminó siendo adoptado en mayor cantidad por los diversos Estados parte, en un proceso de simbiosis entre el derecho internacional de los derechos humanos y el derecho constitucional, lo que generó la internacionalización del derecho constitucional y la constitucionalización del derecho internacional, y del que Chile está aún al debe, pese incluso a la reforma constitucional de 1989.

De igual importancia ha sido la consolidación, en el ámbito regional americano, del llamado «control de convencionalidad», análogo al «control de constitucionalidad»: si los órganos jurisdiccionales, en sede interna, están encargados de velar por el cumplimiento del principio de supremacía constitucional, el juez interamericano debe hacer el control de convencionalidad para verificar que los actos de los Estados parte del sistema interamericano de derechos humanos se ajusten a los parámetros establecidos tanto por la Convención Americana de Derechos Humanos con el resto del corpus normativo interamericano e internacional en la materia. Pero, además, la propia evolución del control de convencionalidad habla del rol protector que le cabe al órgano jurisdiccional interno, cuando las demás funciones o poderes del Estado no dan cuenta de la protección que les corresponde de los derechos humanos.

Estamos ante un doble testeo de la labor del juez local, en el que los derechos humanos se revalorizan en términos axiológicos, punto esencial de la pretendida nueva conformación del Estado chileno, a la luz del proceso constituyente en curso.

\section{Un mayor rol de los abogados en la formulación de litigios estratégicos}

También ha sido importante el rol cada vez más protagónico del abogado litigante, a partir de la comprensión de la pluralidad de normas jurídicas con que cuenta en la actualidad, especialmente a partir de la consolidación de los derechos sociales.

Base de aquello es el litigio estratégico - nacido en la tradición jurídica estadounidense (Frank, 1933) - , cuya pretensión es la de «aterrizar el derecho internacional de los derechos humanos a nivel nacional de manera que se haga realidad el goce de los mismos» (OACNUDH, 2007: 7), aunando la labor del abogado en el foro y la participación ciudadana en su demanda por la justiciabilidad de los derechos humanos (CELS, 2008: 14).

El litigio estratégico implica la selección de un caso de alto impacto con el cual acudir a los órganos jurisdiccionales y conseguir una sentencia que, más allá de reparar a las víctimas directas del caso en cuestión, permita conseguir reformas legales, políticas públicas ad hoc o cambiar la conducta de las autoridades, lo que permite que los beneficiarios finales del litigio sean todas aquellas personas que se encuentren en 
una situación similar (Duque, 2014: 9); la aplicación del principio de precaución, para prevenir o evitar daños a los derechos humanos; y, de forma correctiva, en caso de violación de algún derecho humano, la reparación integral del daño causado.

\section{El activismo judicial en el actual contexto mundial y constituyente nacional}

El desmantelamiento del estado de bienestar, en el marco de la globalización neoliberal, dejó profunda huella manifestada por la crisis económica de 2007-2008 y la actual crisis pandémica por el covid-19. Estos fenómenos dieron cuenta de las consecuencias de la falta de políticas públicas efectivas, así como de una institucionalidad suficiente, que permitiesen resolver los fallos del mercado y las afectaciones profundas en las actividades de las personas y los Gobiernos, especialmente en los sectores más vulnerables.

Si bien la posibilidad de riesgo de contagio sintomático y de letalidad del covid-19 depende del sistema inmunológico de cada persona, independiente de su clase social, tampoco es menor el hecho de que los sectores con mayor riesgo, por falta de atención de los sistemas de atención hospitalaria públicos, la falta de suministros de agua potable, la pérdida de empleos, entre otros, son más vulnerables a los efectos diversos que la dimensión de una pandemia, y requieren de la presencia del Estado en cuanto mecanismo que le permita accionar políticas públicas que puedan compensar sus carencias particulares frente a los abusos del mercado.

Aquello puede implicar, a nivel mundial, una reactivación del estado de bienestar $y$, por ende, del rol en la justiciabilidad de los derechos humanos (sobre todo en los económicos, sociales y culturales) de los órganos jurisdiccionales, tal como en su momento lo han identificado, en sendos documentos, tanto la Cepal ${ }^{6}$ como otros organismos internacionales.

Esto adquiere latente urgencia en el proceso constituyente que vive nuestro país, dimensionado por la serie de exigencias enmarcadas en el fin del proceso neoliberal (detonado a partir de la pasada dictadura cívico-militar). Recordemos, solo de manera somera, y dentro de los múltiples factores que forman parte de las demandas sociales, los grandes rezagos generados de lo que se ha denominado como «sindemia»,

6. Véanse los informes de Cepal, en los que se señala que «la única opción estratégica en el mediano plazo para mitigar los efectos del covid-19 en la región es avanzar hacia un nuevo modelo de desarrollo a través de una mayor integración». «América Latina y el Caribe ante la pandemia del covid-19: Efectos económicos y sociales», Comisión Económica para América Latina y el Caribe, abril de 2020, disponible en https://bit.ly/2T8joQY; «La única opción estratégica en el mediano plazo para mitigar los efectos del covid-19 en la región es avanzar hacia un nuevo modelo de desarrollo a través de una mayor integración», Comisión Económica para América Latina y el Caribe, 3 de abril de 2020, disponible en https:// bit.ly/3xFTOSu. 
es decir, la triple crisis social, sanitaria y económica; y su efecto en la salud mental, 7 vinculados a los efectos nocivos de un Estado subsidiario que dejó al mercado los derechos sociales, y la consecuente desigualdad estructural en nuestro país, especialmente en el delicado panorama económico que genera la actual crisis. Esto se agrava con la temporal supervivencia del ordenamiento constitucional y normativo secundario actual, por lo menos hasta mediados del 2022, con la eventual entrada en vigor del nuevo texto constitucional, y por tanto el parámetro de exigencia y justiciabilidad de los DESCA con coto cerrado en los márgenes de actuación de la actividad jurisdiccional, aún inscrita en el esquema paleopositivista refererido por Ferrajoli, lo que puede graficarse en el conflicto de competencias recientes entre los órganos jurisdiccionales ordinarios y el Tribunal Constitucional. ${ }^{8}$

En dicho contexto, parece más adecuado el impulso al activismo judicial, idea que suele reflotar en tiempos de crisis económica, como ha señalado el profesor HansRudolf Horn (2010: 187). Es un tema clave, tanto al mayor nivel de exigibilidad de los derechos - en general- que tiene la sociedad chilena actual, cuyo potencial ha quedado en claro con las diversas demandas desde octubre de 2019, así como el rol que corresponderá a jueces ordinarios y de control de constitucionalidad en el proceso de justiciabilidad y exigibilidad de los derechos en general y de los derechos fundamentales en particular, a partir de los resultados derivados del proceso constituyente.

Otro punto no menor ocurriría, eventualmente, en una atenuación de las competencias del Poder Ejecutivo, lo que puede conllevar a un mayor control horizontal (check and balances) y una redistribución de competencias en los poderes Legislativo y Judicial, así como una revisión del control constitucional, independiente de los órganos constitucionales autónomos y de participación ciudadana que surjan en el nuevo orden constitucional. Acá parece más razonable, en un marco en el que el reforzamiento en derechos humanos sea el eje del principio de legalidad, que el rol del órgano jurisdiccional en un Estado constitucional de derecho revitalizado tenga una nueva dimensión.

\section{Conclusiones}

Como se puede observar, el alcance del activismo judicial ha superado con creces las aprehensiones que han caracterizado la discusión al respecto.

El rol del juzgador, con mucho, sigue siendo el de protección y reserva normativo-

7. Álvaro Jiménez Molina, Fabián Duarte y Graciela Rojas, «Sindemia, la triple crisis social, sanitaria y económica; y su efecto en la salud mental», Ciper, 20 de junio de 2020, disponible en https://bit. ly/35UBfgv.

8. Juan Carlos Ferrada Bórquez, «Conflicto entre el TC y la Corte Suprema: ¿No será que el origen del problema es el Tribunal Constitucional?», El Mostrador, 17 de octubre de 2019, disponible en https:// bit.ly/3ei1SBo. 
jurídico, bajo la comprensión de la preservación de las facultades que corresponden en el marco del Estado de derecho a cada órgano del Estado. También es necesario establecer un mayor ejercicio de formación judicial profundizado en dos ejes esenciales: derechos humanos y argumentación jurídica, labor que ha cumplido la Academia Judicial, ${ }^{9}$ pero que podría complementarse con protocolos de actuación específicos en materia de derechos humanos para los funcionarios judiciales, como es la experiencia ya dada, entre otras, por el Poder Judicial de la Federación mexicano. ${ }^{10}$

El rol del juzgador hace rato dejó de tener el talante secundario en el ejercicio de las actividades del Estado y, desde la consolidación del Estado constitucional de derecho, adquiere un rol mayor en el ejercicio necesario de velar por el respeto, garantía, promoción y protección de los derechos humanos; dicho rol se ve reforzado con el proceso de adecuación interna del derecho internacional de los derechos humanos, así como del control de convencionalidad.

El Poder Judicial, en el ejercicio cotidiano de sus actividades, se convierte en el enlace directo del Estado con las pretensiones de la ciudadanía, y el medio idóneo para asegurar la justiciabilidad de los derechos humanos. Esto adquiere relevancia en tiempos concurridos por diversas crisis, sanitarias, económicas o de otra índole, en que el Poder Judicial parece como el último bastión operativo ante poderes Ejecutivo y Legislativo muchas veces amarrados a los actos políticos coyunturales o a los vaivenes que dictan los mercados internacionales.

Es cierto que no se trata de una varita mágica que se resuelva de un cambio constitucional - aun de fondo, como parece que se viene-. El rol del juez deberá seguir siendo, qué duda cabe, el de protección del corpus legal de cada país, como el nuestro; asimismo, el lidiar con una tradición de enseñanza y actuación aún acendrada en el iuspositivismo. Pero tampoco cabe duda de que el reforzamiento del corpus internacional de los derechos humanos se convierte en un arma que refuerza el ejercicio del derecho en un Estado constitucional de derecho respetuoso de la vida humana. Las experiencias divergentes, en las resoluciones de los órganos jurisdiccionales y constitucionales de Colombia, Ecuador y Bolivia, en los años recientes, dan cuenta de los retos y desafíos que implica esta tarea a la que Chile se ve enfrentado.

La tarea, dentro del futuro proceso constituyente, que se otorgue al Poder Judicial, así como a otros órganos con competencia jurisdiccional (como el control constitu-

9. Coincido con lo señalado, en su momento, por el exministro de la Corte Suprema, Carlos Cerda respecto de que la creación de la Academia Judicial ha sido la mejor inversión que hizo el Estado chileno a nivel institucional post dictadura cívico-militar. Véase «Noticiero Judicial: Entrevista al próximo ministro de la Corte Suprema, Carlos Cerda Fernández», canal de Youtube de Poder Judicial Chile, 2 de mayo de 2014, disponible en https://youtu.be/cuFGtdWqg5M, especialmente desde el minuto 2:55.

10. Véase «Protocolos de actuación», Suprema Corte de Justicia de la Nación, Derechos Humanos, disponible en https://bit.ly/3wKORqu. 
cional, la Contraloría General de la República o, eventualmente, un ombudsperson), deberá tener en cuenta una salida necesaria del formalismo iuspositivista, considerando el activismo judicial no como una labor que atenta en contra del Estado de derecho, sino como un fortalecimiento efectivo del Estado social y constitucional de derecho, a través de mecanismos que garanticen la exigibilidad y justiciabilidad de los DESCA, así como que permitan romper tendencias autoritarias y represivas en el ejercicio del poder estatal.

\section{Referencias}

Alterio, Ana Micaela (2014). «Corrientes del constitucionalismo contemporáneo a debate». Problema: Anuario de Filosofía y Teoría del Derecho, 8: 227-306. DOI: 10.22201/iij.24487937e.2014.8.8166.

Aguiló Regla, Josep (2013). «Ética judicial y Estado de derecho». En María Cristina García Pascual (coordinadora), El buen jurista: Deontología del derecho (pp. 7176). Valencia: Tirant lo Blanch.

Atienza, Manuel (2019). Siete tesis sobre activismo judicial. Alicante: Universidad de Alicante. Disponible en https://bit.ly/2VTluTe.

BARAONA, Jorge (2010). «La cultura jurídica chilena: Apuntes históricos, tendencias y desafíos». Revista de Derecho (Pontificia Universidad Católica de Valparaíso), 35: 427-448. DOI: 10.4067/So718-68512010000200013.

BARAK, Aharon (2006). The judge in a democracy. New Jersey: Princeton University.

Breyer, Stephen (2017). Cómo hacer funcionar nuestra democracia. El punto de vista de un juez. Ciudad de México: Fondo de Cultura Económica.

Cappelletti, Mauro y Brian Grant (1987). El acceso a la justicia: Movimiento mundial para la efectividad de los derechos. Ciudad de México: Fondo de Cultura Económica.

CARPIZO, Jorge (2002). «Derecho constitucional». En Miguel Carbonell (coordinador), Diccionario de derecho constitucional (pp. 145-147). Ciudad de México: Porrúa-UNAM.

CELS, Centro de Estudios Legales y Sociales (2008). Litigio estratégico y derechos humanos: La lucha por el derecho. Buenos Aires: Siglo XXI.

DuQue, César (2014). «¿Por qué un litigio estratégico en derechos humanos?». Aportes Andinos. Revista de Derechos Humanos, 35: 9-23. Disponible en https://revistas. uasb.edu.ec/index.php/aa/article/view/567

Epp, Charles R. (2013). La revolución de los derechos: Abogados, activistas y cortes supremas en perspectiva comparada. Buenos Aires: Siglo XXI.

Feoli Villalobos, Marco (2015). «El nuevo protagonismo de los jueces: Una propuesta para el análisis del activismo judicial». Revista de Revista de Derecho (Universidad Católica del Norte), 22 (2): 173-198. Disponible en https://bit.ly/3hEMKjp. 
Ferrajoli, Luigi (2003) «Pasado y futuro del Estado de derecho». En Miguel Carbonell (editor), Neoconstitucionalismo(s) (pp. 13-30). Madrid: Trotta-UNAM.

-. (2016). Derechos y garantías: La ley del más débil. Madrid: Trotta.

Fix Fierro, Héctor (2021). «Activismo judicial». En Eduardo Ferrer Mac-Gregor, Fabiola Martínez Ramírez, Giovanni A. Figueroa Mejía y Rogelio Flores Pantoja (coordinadores), Diccionario de derecho procesal constitucional y convencional: 1001 voces in memoriam Dr. Héctor Fix-Zamudio (pp. 54-56). Tomo 1. Ciudad de México: UNAM.

Frank, Jerome (1933). «Why not a clinical Lawyer-School?». University of Pennsylvania Law Review, 81: 907-923. Disponible en https://bit.ly/2TaZKUt.

Horn, Hans-Rudolf (2010). "Activismo judicial versus gobierno democrático». Anuario Iberoamericano de Justicia Constitucional, 14: 183-192. Disponible en https://bit.ly/36yyBhv.

Mejía TuRizo, Jorge y Roberto Pérez Caballero (2015). «Activismo judicial y su efecto difuminador en la división y equilibrio de poderes». Justicia, 27: 30-41. DOI: $10.17081 /$ just.3.27.319.

Montesquieu (2010). El espíritu de las leyes. Ciudad de México: Porrúa.

Novoa Monreal, Eduardo (1981). El derecho como obstáculo al cambio social. Ciudad de México: Siglo XXI.

OACNUDH, Oficina en México del Alto Comisionado de las Naciones Unidas para los Derechos Humanos (2007). El litigio estratégico en México: La aplicación de los derechos humanos a nivel práctico. Ciudad de México.

Toro Vera, Bernardo José (2018). «El juez del Estado constitucional de derecho y el sistema interamericano de derechos humanos». Revista IIDH, 68: 201-226. Disponible en https://bit.ly/3hAPvsf.

\section{Sobre el autor}

Bernardo José Toro Vera es abogado, especializado en derecho constitucional y derechos humanos. Licenciado en Derecho por la Universidad Nacional Autónoma de México. Candidato a magíster en Derecho Constitucional por la UNAM. Diplomado en Formación al Sistema Interamericano de Derechos Humanos y diplomado en Litigio Estratégico en Defensa de los Derechos Económicos, Sociales y Culturales, ambos por el Instituto de Investigaciones Jurídicas de la UNAM. Su correo electrónico es berjotorov@gmail.com. (D) https://orcid.org/0000-0003-1628-8056. 
El Anuario de Derechos Humanos es una publicación semestral de referencia y consulta en materia de derechos humanos y campos afines. Busca ser un espacio de discusión de los temas centrales en el ámbito nacional e internacional sobre derechos humanos. Es publicado desde 2005 por el Centro de Derechos Humanos de la Facultad de Derecho de la Universidad de Chile.

\author{
EDITORA \\ Claudia Iriarte Rivas \\ ciriarter@derecho.uchile.cl \\ SITIO WEB \\ anuariocdh.uchile.cl \\ CORREO ELECTRÓNICO \\ anuario-cdh@derecho.uchile.cl \\ LICENCIA DE ESTE ARTÍCULO \\ Creative Commons Atribución Compartir Igual 4.o Internacional
}

\author{
\% \\ La edición de textos, el diseño editorial \\ y la conversión a formatos electrónicos de este artículo \\ estuvieron a cargo de Tipográfica \\ (www.tipografica.io)
}

